\title{
Resolução de conflitos internacionais: o caso da Noruega como novo ator político
}

\author{
Orides Mezzarroba* \\ Danielle Jacon Ayres Pinto**
}

\begin{abstract}
Sumário: Introdução; 1. Resolução de conflitos: o "modelo norueguês"; 3. A atuação da Noruega em processos de paz; 4. Os ganhos da participação norueguesa em processos de resolução de conflitos. Considerações finais. Referências.
\end{abstract}

\begin{abstract}
Resumo: O texto vai debater as questões da paz e da segurança internacional, trazendo como foco principal a atuação do Estado da Noruega como mediador de conflitos. O intuito é introduzir um novo papel político do Estado no cenário da resolução de conflitos e salientar os moldes como essa mediação é praticada pela Noruega. Todavia, também serão abordados os ganhos que essa participação proporcionará ao Estado norueguês e, como esses são utilizados para promover os interesses nacionais da Noruega no sistema internacional.
\end{abstract}

Palavras-chave: mediação, resolução de conflitos, processos de paz, Soft Power.

\begin{abstract}
The text wil discuss matters of peace and international security, bringing as the main focus the Norway's perfomace like peace-makers. The order is introduce a new political way of the State in conflict resolution and show the Norwegian model of peace-making. Nevertheless, it also intends to show the benefits, for Norway, in that process and show how this benefits are used for promote the Norway's national interest in international system.
\end{abstract}

Keywords: Mediation, Conflict resolution, Peace process, Soft power.

\section{Introdução}

A problemática da segurança e da paz internacional tem se colocado como uma das questões mais importantes na agenda dos atores políticos internacionais. O grande desafio nessa discussão é como buscar a paz diante de intervenções políticas ou humanitárias em determinados conflitos, sem que isto venha a desencadear novos embates políticos.

O presente texto objetiva analisar a forma de atuação da Noruega como importante ator político no cenário internacional da resolução de conflitos e, fundamentalmente, como esta participação está proporcionando a esse país um papel diferenciado nas relações internacionais.

\footnotetext{
* Professor dos programas de Graduação e Pós-Graduação em Direito da Universidade Federal de Santa Catarina. Pesquisador CNPq.

** Graduada e Mestranda em Relações Internacionais pela Universidade de Coimbra.
} 
Para analisar tal inserção, a questão-chave a ser observada é a de como a Noruega molda, em nível político, sua participação em processos de resolução de conflitos. Através da construção de parâmetros de política externa, aquele Estado vem traçando bases sólidas para legitimar sua atuação tanto interna como externamente.

Com o objetivo de fortalecer os paradigmas da paz e da segurança internacionais, a política da Noruega busca uma maior cooperação não só em nível estatal e institucional, mas também com os novos atores não-estatais inseridos no contexto internacional, como ONGs e institutos de pesquisa universitários e independentes.

A política norueguesa não tem o intuito de agir isoladamente: sua especificidade parte do interesse em desenvolver um trabalho conjunto com algumas instituições, dentre elas ONU e OTAN. Por outro lado, a Noruega tem conseguido ao longo dos anos, no pós-Guerra Fria, se colocar como ator individual credível em processos de paz e na resolução de conflitos.

O comportamento norueguês será abordado a partir de duas problemáticas distintas: a primeira alicerçada nos pilares do liberalismo, onde as concepções do "modelo norueguês" são edificadas, e a segunda envolvendo a teoria construtivista, baseada no pensamento de Alexander Wendt ${ }^{1}$, analisando a participação norueguesa frente ao cenário que se apresenta, e que considera as interações sociais entre os agentes e a estrutura em que se inserem.

O que se verifica, no entanto, é que o interesse da Noruega não é de todo altruísta. Sua participação na resolução de conflitos visa aumentar a influência do país no sistema internacional e garantir um canal de diálogo para a defesa dos seus interesses nacionais.

O interesse em instituir um canal de diálogo foi um dos fatores que tornaram a Noruega um ator político imprescindível no cenário de resolução de conflitos na década de 1990, fazendo com que seus propósitos, mesmo não sendo puramente altruístas, se tornassem importantes para a construção de uma paz sólida e duradoura em locais conflituosos.

Ao abordar tais temas, a primeira parte do texto elucidará os parâmetros da política externa norueguesa para a resolução de conflitos, o chamado "modelo norueguês" e sua importância para a atuação da Noruega em conflitos pelo mundo. $\mathrm{Na}$ segunda parte do texto serão identificados alguns casos concretos em que a Noruega foi convidada a atuar. A terceira parte, por fim, abordará os ganhos políticos diretos e indiretos tanto para o processo de resolução do conflito em si como para os interesses da própria Noruega.

${ }^{1}$ Anarchy is what State Make of it: The Social Construction of Power Politics. International Organization. n. 46, p. 391-425, 1992. 


\section{Resolução de conflitos: o "modelo norueguês"}

Com o término da Guerra Fria, a Noruega surgiu como importante ator político no âmbito dos processos de paz em nível internacional. Sua participação em tal cenário foi fundamental não só pelo evidente aumento dos conflitos armados - na grande maioria internos - que surgiram na década de 1990, mas também pela importância e eficácia que sua atuação trouxe para a resolução dos embates.

A participação da Noruega é construída com o intuito de promover a paz, a reconciliação e o desenvolvimento refletidos nos pressupostos da solidariedade humana e no respeito aos valores indivíduais (JOHANSON, 2006). A proposta da Noruega é trabalhar com o intuito de garantir a paz e a segurança internacionais, assumindo ser essa uma responsabilidade de toda a comunidade internacional e não só de instituições como a ONU (MINISTÉRIO DOS NEGÓCIOS ESTRANGEIROS DA NORUEGA, 2007).

Para atingir seus propósitos, a Noruega desenvolveu o conceito de uma política de engajamento, no qual procura justificar a importância da intervenção como forma de prevenir e resolver conflitos armados.

De acordo com o atual ministro dos Negócios Estrangeiros da Noruega, a política de engajamento do país está centrada nos pressupostos de que: (a) os conflitos não são isolados e tendem a se espalhar se não houver envolvimento da comunidade internacional; (b) auxiliando os Estados conflituosos, o país estará se auto-ajudando, já que conflitos locais tendem a criar reflexos globais; (c) se recursos militares forem necessários, eles devem ser utilizados a partir de um planejamento político e econômico que vise a restauração sistêmica do Estado envolvido; (d) o soft power ${ }^{2}$ deve prevalecer sobre o hard power; e (e) todo Estado tem direito de se proteger diante de possíveis ameaças terroristas, desde que considere as conseqüências que tal proteção pode gerar no sistema internacional (STORE, 2007).

Frente aos pressupostos da política de engajamento é que se estrutura a política norueguesa pela paz, que passa a se sustentar em torno de três premissas básicas:

\footnotetext{
${ }^{2}$ Soft Power é um termo utilizado nas relações internacionais para definir um modo de interação entre Estados que não passa pelo uso de forças militares ou hard power. Para que se caracterize o soft power é necessário que se privilegie mecanismos pacíficos e cooperativos, principalmente as instituições de um Estado e seus valores culturais, para que isso possa influenciar os atores no sistema internacional. O conceito de soft power foi desenvolvido pelo teórico norte-americano Joseph Nye, com o objetivo de analisar a construção da política externa norte-americana e como ela era deficitária na utilização do soft power. Ver: Joseph Nye (2004) Soft Power: The Means to Success in World Politics; Joseph Nye (2005) The paradox of American Power.
} 
1. Fortalecimento do Direito Internacional;

2. desenvolvimento de parcerias com outros atores do sistema político internacional; e

3. promoção da paz e do desenvolvimento nos locais em que a Noruega atue como parte interveniente (STORE, 2007).

$\mathrm{Na}$ proposta política norueguesa para a paz fica evidenciada a presença da vertente liberal - a qual, após a Segunda Guerra Mundial, passou a defender a idéia de construção de uma ordem cooperativa e harmoniosa entre os Estados, como forma de promover o desenvolvimento, além de um cenário internacional de paz e segurança (NOGUEIRA; MESSARI, 2005).

Na busca desta cooperação e desenvolvimento, Johanson (2006, p.1) argumenta que a política para a paz patrocinada pela Noruega tem traduzido parte da sua política de segurança, "onde a ajuda provida aos outros pode ser uma ajuda a nós mesmos, como membros de um mundo globalizado".

Tal política de paz, entretanto, necessita de fundamentos sólidos de sustentação para que não se torne apenas uma linha de ação externa, sem produzir resultados efetivos no cenário político internacional.

Neste sentido, o governo norueguês fundamenta sua ação para promover a política de paz em seis pontos:

(a) Consistência - ou seja, esforços prolongados ao longo de diferentes governos;

(b) vasta abordagem dos esforços de paz, através de amplos acordos políticos entre as partes conflitantes;

(c) interação entre assistência humanitária, cooperação para o desenvolvimento e esforços de paz;

(d) cooperação com ONGs e institutos de pesquisa noruegueses, aos quais cabe instigar e promover o envolvimento da Noruega em processos de paz;

(e) reproduzir os valores noruegueses em processos de paz, enfatizando suas características de imparcialidade, embora sem neutralidade em questões como violações de direitos humanos e do direito humanitário consagrados internacionalmente; $\mathrm{e}$,

(f) por fim, a relevância da cooperação internacional entre os mais diversos atores políticos (STORES, 2007). 
Após delinear os fundamentos da política norueguesa para a paz, cabe exemplificar na prática a ação da Noruega em caso de conflitos armados. A forma de atuação do país nesse cenário divide-se em três momentos:

(a) Apoio ao processo de negociação entre as partes conflituosas;

(b) apoio aos mecanismos de monitoração para garantir o cumprimento dos compromissos negociados; e

(c) apoio a medidas urgentes de reconstrução das zonas devastadas pelo conflito (MINISTÉRIO DOS NEGÓCIOS ESTRANGEIROS DA NORUEGA, 2007).

A partir desta estrutura teórica da política para a paz pode-se falar, então, sobre o "modelo norueguês" de resolução de conflitos. Modelo que se reveste de características que levam a Noruega a ser considerada um peace broker ${ }^{3}$ nas situações de conflitos armados e que a está convertendo numa referência mundial na resolução dos mesmos.

De acordo com Hanssen-Bauer (2005), “as regras da Noruega como facilitador da paz seguem uma longa tradição de suporte dos mandatos para paz e segurança da ONU". Nos conflitos em que a atuação da ONU se revela ineficaz, porém, a Noruega se apresenta como ator político diferenciado (STORE, 2007).

Diante do exposto pode-se apresentar o "modelo norueguês" com as seguintes características básicas:

(a) ser um facilitador paciente: pela consistência do seu trabalho para a promoção da paz, evitando que, por ação da própria Noruega, os processos se tornem inconclusos;

(b) disponibilidade de recursos: por proporcionar grande flexibilidade, ao dispor de recursos financeiros e humanos em curto espaço de tempo, o que torna seu engajamento rápido e eficaz;

(c) cooperação com ONGs nacionais e internacionais: o que facilita o reconhecimento dos problemas locais e a eficácia das ações a ser executadas;

(d) interação entre a diplomacia e a assistência humanitária, bem como entre governo e atores não-governamentais: o que possibilita a criação de parcerias mais eficazes na construção do processo de paz;

\footnotetext{
${ }^{3}$ Expressão que se pode traduzir como "facilitador da paz".
} 
(e) caráter imparcial: reconhecimento como um facilitador da paz sem interesses políticos ou econômicos direitos nas zonas em conflito;

(f) relações de proximidade com importantes e reconhecidos atores internacionais: pelo fato de a Noruega possuir uma ampla rede de contatos e acesso a atores internacionais, o que pode facilitar sobremaneira a restauração do diálogo entre as partes conflituosas (HANSSEN-BAUER, 2005).

É sobre tais parâmetros, portanto, que a Noruega alicerça sua participação política em processos de promoção da paz e segurança internacionais, como também pela compreensão de que sua própria segurança depende da inexistência de conflitos armados e do fortalecimento da segurança internacional.

Dentro da proposta norueguesa pode ser inserida, ainda, a idéia de se evitar novos conflitos através da formação de instituições viáveis e de instrumentos de boa governança, com legitimidade para promover a distribuição igualitária do poder político e econômico. Essas seriam as condições imprescindíveis para se evitar déficit de governação e o (re)aparecimento de conflito em proporções ingerenciáveis (STORE, 2007).

A leitura norueguesa é a de que os conflitos locais também são problemas globais (JOHANSEN, 2006). Diante disso, uma política de não-envolvimento e a inexistência de diálogo não representam opção para a resolução do problema, sendo necessários maior comprometimento e a ação conjunta de todos os atores políticos em prol da paz no sistema internacional (STORE, 2007).

\section{A atuação da Noruega em processos de paz}

A década de 1990 foi marcada pela ampliação de conflitos armados em várias partes do mundo e por outra especificidade: a dos conflitos intraestatais, nos quais os governos institucionalizados e grupos rebeldes nacionais lutam pelo controle do poder político.

Tal cenário favorecerá a Noruega a desenvolver e executar sua proposta de resolução de conflitos - a qual, em poucas palavras, pode ser definida como uma forma de fortalecimento da cooperação entre governo e entidades não-governamentais (EGELAND, 1994).

A participação da Noruega tem seu marco inicial nos Acordos de Oslo de 1993, envolvendo Israel e Palestina, e a partir de então sua atuação se ampliou para outras regiões, dentre as quais Guatemala, Afeganistão, Haiti, Colômbia, Chipre, Sudão e Sri Lanka. 
Para que se compreenda melhor a atuação norueguesa serão analisados dois momentos de sua participação: o conflito Israel-Palestina e o do Sri Lanka. A idéia é referir algumas características já mencionadas acerca da forma de atuação da Noruega na tentativa de solucionar os dois conflitos.

No processo israelo-palestianiano, a Noruega foi responsável pela chamado Oslo-Channel (HANSSEN-BAUER, 2005), que serviu como suporte e canal secreto para as já iniciadas conversações de paz lideradas pelos Estados Unidos (EGELAND, 1994).

A ação do governo norueguês não ocorreu de forma isolada, contando com a participação direta do $\mathrm{FAFO}^{4}$, instituto de pesquisa e estudo que desde a década de 1980 trabalha no mapeamento das condições de vida dos palestinos que vivem em territórios de ocupação israelense. A pesquisa forneceu dados mais aprofundados sobre as necessidades locais e o processo de interação entre os atores conflituosos. Foi esse um dos fatores determinantes para a concretização da Declaração de Princípios de Oslo, assinada na Casa Branca, em Washington, a 13 de setembro de 1993 (HANSSEN-BAUER, 2005).

Na prática, a FAFO estruturou sua participação de modo eficiente e discreto, num trabalho que incluiu desde apoio logístico, como reserva de hotéis e manutenção de redes de contato através dos meios de comunicação, até a organização de reuniões para o planejamento das conversações de paz que redundaram na elaboração na Declaração de Oslo de 1993. Por sua vez, coube ao governo norueguês fornecer todo o aparato político e os recursos para que a FAFO usufruísse de maior prestígio e credibilidade (EGELAND, 1994).

No caso do Sri Lanka, a atuação da Noruega será ainda mais participativa, visto que atuou como hábil facilitador para o recomeço da negociação política entre o governo daquele país e os Tigres da Libertação da Pátria Tamil - LTTE 5 , o que resultou no Memorando de Entendimento firmado em 2002 e que serviu de base para as negociações de paz que perduram até o presente momento (CRAVO, 2005).

O Memorando tinha por objetivo estabelecer um cessar-fogo, fazendo com que ocorresse uma imediata redução da violência que afetava a população do Sri Lanka. Com isso se buscava criar um ambiente de maior estabilidade para negociar um acordo de paz.

Para alcançar tal objetivo foi criada uma missão de monitoramento no Sri Lanka, com a intenção de verificar in loco o cumprimento do Memorando. A missão foi composta por representantes da Noruega, membros do governo do Sri Lanka

\footnotetext{
${ }^{4}$ Instituto norueguês de pesquisa e estudo internacionais. Outras informações conferir www.fafo.no.

${ }^{5}$ LTTE significa Libertation Tiger of Tamil Eelam.
} 
e representantes do LTTE. O resultado foi altamente positivo, implicando um decréscimo, entre junho e setembro de 2002 , de $40 \%$ nas denúncias de violência decorrente do embate entre as partes (HÖGLUND; SVENSSON, 2003).

A atuação da Noruega nesses dois contextos conflituosos materializa o "modelo norueguês" de resolução de conflitos. Com este modelo, a Noruega propicia a inserção de outros atores políticos - como ONGs e institutos de pesquisa - que não os convencionais, como também a interação entre o poder institucionalizado e os grupos marginais.

A proposta norueguesa está muito próxima da visão construtivista de Wendt (1992), quando defende que um sistema de segurança cooperativo, onde um Estado se identifica positivamente com outro, reafirma que a segurança de cada um é percebida como a segurança do todo. Como também que a idéia de que um mundo socialmente construído deve ser produto de concepções e valores dos agentes envolvidos (NOGUEIRA; MESSARI, 2005).

Pode-se concluir, por fim, que será com o envolvimento de vários atores políticos no processo de construção da paz que poderá haver efetiva contribuição para o alcance de soluções mais eficazes, realistas e duradouras em situações de conflitos armados.

\section{Os ganhos da participação norueguesa em processos de resolução de conflitos}

A participação da Noruega nos processos de resolução de conflitos implica ganhos em várias dimensões. A principal envolverá os atores em conflito, mas também será beneficiada a comunidade internacional e, por fim, o próprio Estado norueguês.

A combinação desses ganhos é que permitirá a Noruega tornar-se importante referência como ator político internacional para resolução de conflitos, fazendo com que seus meios de intervenção sejam cada vez mais solicitados em situações onde as partes decidam caminhar na construção da paz.

Para os atores em conflito, a atuação da Noruega proporciona a garantia de uma intervenção imparcial, confiável e consistente para o processo de negociação de paz.

A Noruega goza da imagem de país pacífico e generoso em nível mundial. O país contribui com quase $1 \%$ do seu produto interno bruto para investimentos em projetos de desenvolvimento em Estados periféricos. Também participa, de forma presencial e econômica, em várias etapas do processo de paz, desde da negociação 
de acordos até a reconstrução pós-bélica, e goza de apoio consistente junto à comunidade internacional, o que a credencia como importante canal de conversação com as principais potências mundiais (CRAVO, 2005).

Essas qualidades conferem a Noruega relevante e viável função como ator político em processos que exigem a construção de paz consistente e duradoura. Com isso é crescente a procura, por parte de outros Estados, para que a Noruega intervenha como facilitador na resolução de seus conflitos internos.

Enfim, para a comunidade internacional, essa concepção de intervenção do "modelo norueguês", sustentado pela cooperação entre governo e entidades nãogovernamentais, acabou por trazer novo paradigma aos processos de resolução de conflito e de busca pela paz.

A adaptação da diplomacia a formatos menos convencionais, incluindo institutos acadêmicos e ONGs, fez com que a realidade do terreno conflituoso fosse conhecida mais concretamente, proporcionando com isso a busca de soluções realistas para a construção de sociedades mais estáveis nas zonas em conflito (MOITA; MOITA, 2004).

Neste sentido, conforme Moita; Moita (2004), a multitrack diplomacy vem substituir o modelo tradicional de diplomacia em que todos os esforços internacionais do Estado se concentram nas mãos do ministro das Relações Exteriores e de seu corpo diplomático. O novo modelo de ação implementado pela Noruega, que se enquadra no conceito de multitrack diplomacy, apresenta uma nova estratégia, na qual os recursos logísticos governamentais acabam por servir de apoio a outros atores políticos que não os estatais.

O que se destaca em tal processo é a falta de interesse direto do governo norueguês no conflito, o que representa uma nova alternativa à comunidade internacional para a edificação da paz.

A contribuição para a construção da paz em regiões conflituosas por parte da Noruega não se apresenta, porém, como algo meramente altruísta. Para aquele Estado, cada participação em zonas de conflito é uma janela de oportunidade para o país inserir-se na comunidade internacional como uma "potência moral" (CRAVO, 2005). Assim, mesmo sendo um país de dimensão territorial não muito representativa, a Noruega consegue influenciar o sistema político internacional devido a sua atuação política por meio do soft power e do seu sólido poder financeiro interno.

Na prática, a política norueguesa se destaca por adotar duas estratégias complementares. Uma delas é apresentada por Matlary (apud GREER, 2003), quando busca o caminho para chegar ao centro das decisões políticas mundias, assumindo o papel de facilitador na resolução de conflitos em regiões periféricas, o que lhe dá destaque junto àqueles espaços decisórios pela singularidade e originalidade de suas 
ações; a outra é mencionada por Tonnesson (apud GREER, 2003) e decorre diretamente dos resultados obtidos pela atuação na primeira, quando diplomatas noruegueses aproveitam para falar de assuntos de interesse nacional com outras potências mundiais, a partir dos canais de diálogo abertos pela atuação singular da Noruega em zonas de conflito.

Assim, o envolvimento da Noruega em processos de paz trabalha em mão dupla. Se por um lado sua participação é uma forma diferenciada de se inserir como Estado influente no sistema internacional, por outro e ao mesmo tempo, abre caminho para que os interesses nacionais da Noruega sejam contemplados de maneira mais eficaz.

Em síntese, a presença do "modelo norueguês" em processos de resolução de conflitos cria a perspectiva de um Estado-referência e com credenciais de "potência moral", em condições de atender e atuar significativamente na crescente demanda pela intervenção internacional em conflitos armados.

\section{Considerações finais}

A partir da perspectiva de que a Noruega se apresenta como novo ator na política de resolução de conflitos internacionais, pode-se chegar às seguintes observações.

A atuação da Noruega, mais do que trazer um novo personagem para o campo da busca de soluções para conflitos internacionais, acabou por representar uma forma inovadora e original de atuação em tais cenários. A partir da proposta de uma maior interação entre Estado e organizações não-estatais, a Noruega passou a maximizar a possibilidade de sucesso nos processos de construção de paz, criando, assim, importante precedente para a atuação dos órgãos estatais em zonas conflituosas.

Na medida em que a proposta da Noruega leva em consideração a percepção dos atores envolvidos na própria região conflituosa, fica evidente que o comprometimento norueguês não se restringe à adoção de medidas superficiais que visem o apaziguamento temporário do conflito. Muito pelo contrário, sua determinação está voltada para a busca de soluções sólidas e duradouras de paz entre os personagens litigantes.

A proposta da Noruega não exclui a participação de outros atores internacionais na zona conflituosa, dentre eles a ONU. É nesse aspecto que o estilo norueguês é extremamente inovador. Em sua estratégia, a Noruega trabalha com a idéia de que qualquer ação dos Estados deve ser realizada em parceria com a ONU. No 
entanto, esse tipo de parceria não deve representar um impedimento para eventuais ações praticadas por um Estado isoladamente, quando isto se fizer necessário.

Outro aspecto importante da proposta norueguesa é a compreensão de que os conflitos em outras regiões, mesmo que fora da sua área de influência, também representam uma ameaça para sua segurança interna. Chamar, portanto, a responsabilidade de outros Estados na preservação de um sistema internacional seguro e pacífico é imprescindível para a Noruega. No entendimento desse país, não se pode imputar isoladamente a esta ou àquela organização ou a este ou àquele país a responsabilidade pela preservação da paz no mundo. A responsabilidade é de todos e o esforço pela manuteção da paz em qualquer região da Terra deve também ser de todos os Estados e órgãos internacionais.

Não se pode concluir, entretanto, que a participação da Noruega no cenário da resolução de conflitos internacionais seja marcada exclusivamente pelo desprendimento e altruísmo. Muito pelo contrário: todas as suas ações visam, acima de tudo, produzir efeitos positivos para seus próprios interesses políticos. A participação da Noruega em resolução de conflitos serve, de certa maneira, como estratégia para abertura de canais de conversação com outros Estados, órgãos e potências mundiais. Através da consolidação desses canais de diálogo, a diplomacia norueguesa encontra o espaço necessário para discutir e defender questões que envolvam seus próprios interesses. Assim, com a garantia de usufruir de lugar privilegiado em mesas de conversações, a Noruega pode se dar ao luxo de maximizar em termos absolutos os ganhos políticos sobre os investimentos realizados.

Enfim, a participação da Noruega em resolução de conflitos internacionais possibilita sua inserção no seleto grupo de potências mudiais e em importantes fóruns de decisões políticas e econômicas. Com essa estratégia, o país construiu um novo caminho para sua inserção enquanto importante potência mundial, fugindo dos parâmetros puramente econômicos. Tal eficiêcia garantiu para si a láurea, até então única, de ator eficiente, dotado de métodos de ação eficazes em processos de resolução de conflitos e na garantia da construção da paz mundial.

Pode-se concluir, por fim, que a Noruega se apresenta como novo e importante ator político no tocante à participação de um Estado em cenários de resolução de conflitos e processos de construção de paz. Entretanto, na questão da defesa dos interesses nacionais, o que se vê é uma Noruega realista, que calcula suas ações de maneira a maximizar seus benefícios políticos. 


\section{Referências}

CRAVO, Teresa. A Noruega e o Processo de Paz no Sri Lanka. Janus 2005: A guerra e a paz. Disponível em: <www.ces.uc.pt/nucleos/nep/documentos/ janusTeresaCravo.pdf $>$. Acesso em: 15 out. 2007.

EGELAND, Jan. Norway's Middle East Peace Channel. Security Dialogue. n. 25 (3), p. 349-351, 1994.

GREER, Mark. Norway's Peace Role. Medill News Service, 2003. Disponível em: $<$ http://www.medillnewsdc.com/cg-bin/

ultimatebb.cgi $u b b=$ get_topic $\& \mathrm{f}=35 \& \mathrm{t}=000020>$. Acesso em: 26 out. 2007.

HANSSEN-BAUER, Jon. The Norwegian "model" for conflict resolution.

Conferência sobre o Prêmio Nobel da Paz e o trabalho para paz da Noruega, 2005. Disponível em: <http://www.noruega.org.pt/NR/rdonlyres/EA31107592A7-483B-B905-AF9C0337A2B7/35583/

TheNorwegianmodelJHBALisboaoct2005.doc>. Acesso em: 11 nov. 2007.

HÖGLUND, Kristine; SVENSSON, Isak. The Peace Process in Sri Lanka.

Civil War. n. 5 (4), p. 103-118, 2003.

JOHANSEN, Raymond. Norway's Role in Peace and Conflict Resolution. $\mathbf{2}^{\text {nd }}$

Annual Somali Peace Conference: Good Governance and Rule of Law, 2006.

Disponível em: $<$ http://www.regjeringen.no/en/dep/ud/About-the-Ministry/Otherpolitical-staff/State-Secretary-Raymond-Johansen/Speeches-and-articles/2006/ Norways-Role-in-Peace-and-Conflict-Resolution.html?id=420842>. Acesso em: 26 out. 2007.

MNE - Noruega: Ministério dos Negócios Estrangeiros da Noruega (SD). Os esforços da Noruega em favor da paz e reconciliação em diferentes partes do mundo. Disponível em: $<$ http://www.noruega.org.pt/policy/peace/peace/ peace.htm>. Acesso em: 26 out. 2007.

MOITA, Luís; MOITA, Madalena. Novos intervenientes na guerra e na paz. Painel 19: Novíssimas Guerras, Novíssimas Pazes. VIII Congresso Luso-AfroBrasileiro de Ciências Sociais. p.1-5, 2004.

NOGUEIRA, João Pontes; MESSARI, Nizar. Teoria das Relações Internacionais: Correntes e Debates. Rio de Janeiro: Elsevier, 2005.

STORE, Jonas Gahr. A policy of engagement. Norwegian peace policy. Norman

Paterson School of International Affairs, 2007. Disponível em: $<\mathrm{http} / /$ www.regjeringen.no/nb/dep/ud/dep/Utenriksminister_Jonas_Gahr_Store/ taler_artikler/2007/A-policy-of-engagement-Norwegian-peacepolicy.html?id=456828>. Acesso em: 15 nov. 2007.

WENDT, Alexander. Anarchy is what State Make of it: The Social Construction of Power Politics. International Organization. n. 46, p. 391-425, 1992. 